prisoners engaged in road work, who drank water taken from the bed of the Moola river below the dam."

It will be observed by a reference to the table of employment that the road gang was considerably increased on the 25 th and 26th May; the road had already been metalled, and the extra hands were required to water and roll the road, so that it might not be damaged by the daily expected heavy rains. It should be here stated that a certain number of barrels for storing water and water-carts were sent with the road gang, and that water for drinking purposes was brought to them from above the dam. Five water-carts had been also sent with these men for the purpose of watering the road whilst it was being rolled by others; these carts were filled from the nearest water obtainable-that is, from pools in the nearly dry bed of the river, opposite to the Poona end of the road under construction. The prisoners admitted that they had drunk freely of that water, not only when they filled the carts, but also when they were made to wash before returning to the gaol after their day's task was over. The cholera patients to whom this query was put all unhesitatingly declared that they had partaken freely of it; moreover the warder who was in charge of the carts for supplying them with drinking water corroborated the fact in a remarkable manner; he stated that on the 25 th and 26 th of May he had conveyed to them less water than on the previous days, although the number of prisoners at work on the road was nearly three times as great. "The fact of the road gang drinking water taken from a source different to the one used by the remainder of the prisoners is placed beyond any doubt."

Was cholera communicated to these prisoners through the water they drank? This is the question I will now endeavour to solve.

On the morning of the 29th May Mr. Taylor (the gaoler) and myself visited the locality from which water for watering the road had been taken. The identical spot was shown to us by the warders on duty on the 25 th and $26 \mathrm{th}$, and their testimony was corroborated by our finding there several pieces of gaol clothing. Some 600 or 700 yards above this spot the river is barred; a dam was erected there some years ago for the purpose of securing a constant watersupply to the city of Poona, the river generally running nearly dry during the hot weather. The bed of the river from the dam down wards contained but little water; where we were standing we saw several large semi-stagnant pools, separated from similar small expanses by bugh boulders and moss-covered islets of volcanic rocks; slowly flowing streamlets connected these pools one with another, but on our side of the river-bed the current was so weak that we almost doubted its existence. Between the locality on which we were standing and the dam a number of washermen were at work ; men and women were seen here and there performing their morning ablutions, \&c.; cattle were roaming about; and a glance showed that the bed of the river between the dam and the place from which water had been taken for watering the road must be contaminated by ex. creta of all kinds. The river was not overflowing the dam on that day, and from inquiries we learnt that it had not done so for several days: one of the sluices was open, but on the opposite (Poona) side of the river. Water was taken from the poole above mentioned and forwarded to Dr. Gray, the chemical analyst to Government.*

Cholera existed at the time throughout the province, in Poona, and in the neighbouring villages. In India the bed of a river in the vicinity of a large city is the usual place selected by travellers before entering the town to perform their ablutions, \&e.; washermen are constantly at work in the same locality; in fact, we could hardly expect to find anywhere so many agencies united to contaminate drinking water by means of choleraic discharges, and, irrespective of what the inquiry had already allowed us to surmise, we would have already strong grounds for accepting the outbreak as due to the propagation of cholera through drinking water. In this instance, however, we possess evidence still more direct and positive.

On the 22nd of May two fatal cases of cholera occurred in the village of Yerrowda, situate opposite the dam, and

* Analysis of the water made by Dr. Gray, chemical analyst to Government:-Solid grains per gallon, 10.36 ; chlorine, 95 ; hardness, total, 6.30 ; hardness, permanent, 342 ; oxygen removed by readily oxidizable matter of water at $140^{\circ} \mathrm{F},{ }^{\circ} 072$. Part per million of free ammonia, 0.32 ; of albuminoid ammonia, 022 . we learnt that on the evening of the 22nd these bodies were washed and burnt, and the clothes worn during their fatal illness washed some twenty yards above the spot from which water had been drunk by most of the road gang, and which proved so poisonous and so deadly to many of them.

Poona, July lst, 1875 .

\section{REMARKS ON THE}

\section{ANATOMY AND PA'THOLOGICAL RELATIONS} OF A NEW SPECIES OF LIVER-FLUKE.

By J. F. P. McCONNELL, M.B., PROTESSOR OF PATHOLOGX AND RBSIDENT FHYSTCIAN, MBDICAL COLlegR, CALCUTta.

ON the 9 th of September, 1874, I made a post-mortem examination of the body of a Chinaman, and found in the liver, obstructing the bile-ducts, a large number of "flukes." A careful examination of these, and comparison with other known distomata, have convinced me that they not only differ from the ordinary liver-fluke (Dist. hepaticum), but constitute an entirely new species. I desire therefore to describe the salient anatomical characters of these flukes, then to give a brief account of the post-mortem examination alluded to, and lastly to make a few remarks upon the case.

The woodcuts which accompany this paper will facilitate the description. Fig. 1 represents a few of these flukes drawn to natural size. Fig. 2 is one specimen enlarged to about six times the natural size, showing the ventral surface. Fig. 3 represents the ova magnified 300 diameters.

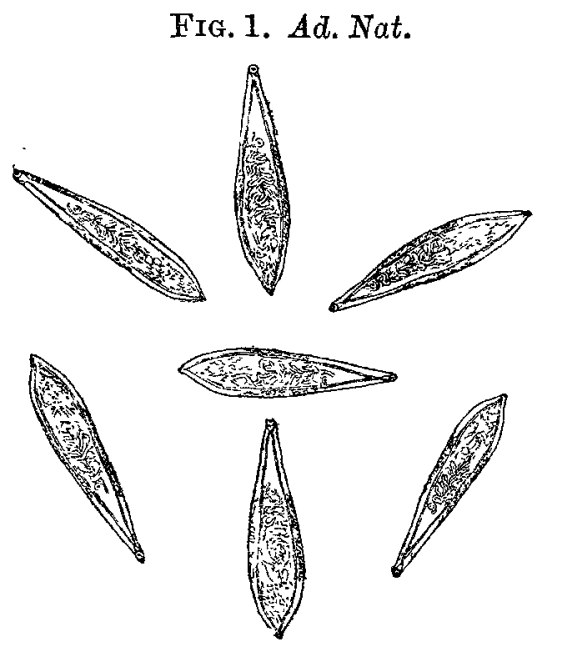

Fig. 3. $\times 300$.

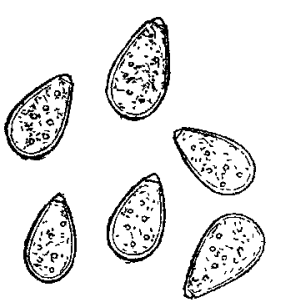

Fig. 2.- $a$. Oral sucker. b. Esophagus. $c, c^{\prime}$. Right alimentary canal. $d$ Ventral sucker. $\epsilon$. Genital orifice. $f$ Uterine folds. $g$. Ovary. $h$. Vitelligen gland (right). $i$. Vitelligene duct (right). $z$. Right testicle. $l$. Recepta culum seminis (?) mi. Left testicle. $n$. Vas deferens. $o$. Termination of vas deferens. $p$. Pulsatile vesicle. $p^{\prime}$ Water-vascular canal.

FIG. 2. $\times 6$

The body is narrow, flattened, lanceolate; the central portion being the broadest part of the animal, the anterior and posterior extremities tapering and pointed, the former however, being much narrower than the latter, which is 
more strictly ovate. The surface of the body is smooth, quite free from hairs or spines even in the fresh condition. The borders have a slightly undulating outline. At the anterior extremity (Fig. 2) is situated the oral sucker (terminal), $a-$ a hollow disc, provided with a well-defined sphincter. At the bottom of this cup-like cavity is the mouth; this leads into the pharynx, $b$ (which is circular or slightly oval-shaped, and is probably muscular), and thence into the cesophagus. The œsophagus bifurcates in the median line of the body (a little distance above the ventral sucker) into two alimentary canals, $c$, which diverge as they pass downwards and outwards along the sides of the body, slightly widening as they proceed, and converge again towards the caudal extremity, close to which they terminate in blind cul-de-sacs, $c^{\prime}$. These canals are unbranched throughout. On the inferior surface of the body is the ventral sucker, $d$; situated in the median line, and about $\frac{1 "}{6}$ (one-sixth of an inch) below the oral sucker. It is imperforate, and provided with a sphincter, the radiating fibres of which can be clearly distinguished. This sucker is slightly smaller than the oral, measuring $\frac{1^{-} \prime}{34}$, whereas the latter is $\frac{1}{25}$.

Just above the ventral sucker is a minute dark dot, $e$, which appears to be the genital orifice. No penis or penislike appendage can be detected, but ova have, in several specimens, been seen to assume a linear arrangement between the little orifice just mentioned and the hollow ventral disc into which they have dropped. Opening into this genital orifice, in favourable specimens, can be traced the delicate tubular termination of a convoluted uterine tube. This structure is highly developed, and consists of a series of very intricate windings, $f$, which communicate posteriorly with a flattened, somewhat square-shaped body, the ovary, $g$. The uterine tubules are semi-opaque, but in the more trans. parent portions numerous ova are seen collected together within the folds. The uterus and ovary occupy rather more than the middle third of the animal.

Occupying the interspaces between the alimentary canal and the lateral borders of the body on either side are the dark, pigmented-looking structures, the vitelligene structures, $h$. These communicate with the ovary by two delicate canals, which run transversely inwards to it, and con. stitute the vitelligene ducts, $i$.

Placed a short distance behind the ovary is a large ovalshaped body, the testis, $k$; which is succeeded by a remarkable and peculiar development of branched, dendritic-looking structures, $l$, among which, in several specimens, a rounded smaller testicle $(\mathrm{m})$ can be distinguished. This apparatus appears to be connected with the male generative organs, and forms perhaps a kind of receptaculum seminis. This is the most marked and distinguishing character of this fluke. The testes and branched receptaculum are of a rusty-brown colour, both of the same tinge, ${ }^{*}$ and have granular amorphous contents; the connexion, however, between this apparatus and the testes is uncertain, but, as far as one can speak from a very careful examination of several specimens, the arrangement is that which has just been briefly sketched. The position and shape of the second or smaller testicle are also very variable. In some of the parasites only one large globular organ of this kind can be discovered; in others, the position of the second testis is lower down the axis of the receptaculum; in others again, instead of a distinctly rounded organ, a mere diffuse "blurring" of one of the branched tubes can be beld to represent this second testicle.

Starting from the upper part of the male generative apparatus, a very delicate thread-like structure can be seen, $n$, which runs upwards by the side of the larger testis to the lower border of the ovary, and probably above it, but can be traced no further. This appears to be the seminal efferent duct, or vas deferens. The point at which it communicates with the female generative apparatus was not for a long time ascertained; but lately, in a specimen stained with carmine, and then pressed between thin pieces of glass, I have been able to discover (what seems to me the continuation of this tubule) a very delicate structure, $o$, curving round the ventral sucker on the opposite side to the termination of the uterine folds, and ending at the same genital orifice, or at a point very close to it, as depicted in the engraving (Fig. 2). As this tubule is a flexible elastic structure, it may very possibly run up the same side

* In the diagram the engraver has made the testicles darker than the rest of the apparatus, and their contents somerwhat largely molecular, but this is not correct. as the uterine tubule, and not occupy an opposite position; I have drawn it, however, exactly as seen in the specimen alluded to.

Lastly, at the caudal extremity of the body of the fluke may be seen a pulsatile vesicle or bulb, $p$, associated with the water-vascular system of the animal; the continuation of the same upwards, in the form of a vascular canal, can be traced for a certain distance, passing above the male generative apparatus in a winding course, and being lost sight of at a short distance to the lef $t$ of the right testicle, $p^{\prime}$. The average length of the distoma now described is $7^{7} \sigma^{\prime \prime}$, and the breadth $\frac{1}{7}$. The latter is very constant; the tormer has slight variations-viz, from $8_{1}^{8} "$ " to ${ }_{10}^{6} "$.

I have not observed any further marked peculiarities in the minute structure and arrangement of the tissues and organs of this particular parasite but what have been described by systematic writers on entozoa; so that I refrain from adding unnecessarily to the length of this paper by giving detailed accounts of microscopic appearances already well known.

The ova are of distinctly ovoid shape (Fig. 3). A short distance from the more pointed extremity is a dark, transverse line, just as is usually seen in the ova of distomata, and indicating the line of contact of that lid-like organ or operculum, which, after a time, spontaneously separates. The average length of each ovum is $\frac{1}{83} 3^{\prime \prime}$, and the average breadth $\frac{7}{1666}$ "; thus, roughly speaking, it is twice as long as it is broad.

The individual from whose liver these flukes were obtained was a Chinaman, aged twenty, a carpenter. He was brought into the Medical College Hospital at midnight on September 8 th, 1874, in an insensible, moribund condition. The only history that could be obtained from the "friend" who accompanied him was, that the patient had been suffer. ing from "fever" of a continued type for about a fortnight. The insensibility was profound; the pupils were normal the conjunctivæ looked pale. There was considerable dyspnoea; a hard, tense, distended, and slightly tympanitic condition of the abdomen; a bot skin, and an almost imperceptible radial pulse. He never rallied, but died, in much the same state, two hours and a half after admission.

A post-mortem examination was made the next morning, fire hours and a half after death, a brief summary of which is as follows:-Body fairly nourished; pupils dilated; conjunctivæ jaundiced; rigor mortis strong in the lower limbs. The dura mater yellow-stained; vessels of pia mater everywhere gorged with dark blood, slight serous effusion also in to its meshes; cerebral substance moderately firm; puncta large and bleed freely; grey matter of both cerebrum and cerebellum particularly dark-a deep leaden hue, such as is met with in many of the severe remittents of this country. The large pulmonary vessels at the roots of the lungs contained much fluid dark blood, but the lung-substance every. where else was rather pale and anæmic-structurally healthy. One ounce of deeply yellow-tinged serum was found in the pericardial cavity; a few dark clots and fluid blood in the right chambers of the heart; the left were almost empty. The peritoneum was healthy, and no effusion was found into the abdominal cavity. The liver was large, swollen, and tense ; superficially of a dark-purple colour, on section paler, more dingy or muddy-looking. Its parenchyma everywhere very soft. The large portal and hepatic veins were filled with fluid blood, and the bile-ducts particularly distinct from their large size, and distension with thick yellow bile. On incising the liver in different directions it was noticed that small, dark, vermicular-looking bodies escaped on to the table, and on more careful examination these were clearly seen to protrude from the bile-ducts, which, on being dissected, were found more or less obstructed by and containing them in large numbers, some lying free, others coiled up, and either solitary or in groups of twos or threes within the biliary ducts; all were dead. The gall-bladder was full; the cystic and cholodic ducts were patent. The bile in the bladder was of a very deep yellow (orange) colour, thick, and measured about an ounce and a half. No distomata were found in the gall-bladder, nor were any ova discovered on microscopical examination of the bile and lining membrane of this sac. Numerous ova and shreds of epithelium were found in the biliary canals. (The weight of the liver after incision was 54.1 oz.) Portions of this organ were hardened, thin sections made, and examined 
microscopically. A most remarkable and intense pigmentation of the parenchyma was observed-not mere staining, but a positive infiltration of black pigment, granular in character, and not confined or specially distributed in the interlobular tissue, but occupying the hepatic cells also within the lobules; the greater portion being disposed in the form of minute, very dark, granular depôts, from which smaller molecules radiated in all directions as from a centre. The pigment matter appeared to be biliary rather than hæmatoid. Many of the hepatic cells were also infiltrated with fat, and the nucleus in the majority was ill-defined or altogether indistinguishable. The spleen was found enlarged; its capsule stretched, slightly thickened, and opaque; its substance very dark and pulpy; weight 13 13 oz. The kidneys were moderately hyperæmic and dark. The small intestines were found deeply bile-stained; the large, natural. The fæcal contents of both-partly solid and partly liquid-were bile-coloured, but no distomata were found in them, although carefully washed and examined.

Remarks. -The morbid anatomy of the liver in this case seems unequivocally to point to the presence of the flakes in its biliary ducts as the exciting canse of the acute and extensive structural degeneration of the proper structure of the organ, and of that cholæmic condition induced by the obstruction of the biliary channels which appears to have bean the immediate cause of death. It is noticeable that the gall-bladder itself contained no distomata, nor exhibited any evidences of having been occupied by them, while the bile-ducts were found densely crowded. I must have collected at least thirty specimens in my dissections, and numbers doubtless still remain in those portions of the liver which I have preserved entire, for hardly any duct of medium size has not been found to contain two, three, or more of these parasites.

The discovery of this distoma may perhaps throw some light upon the pathology of those obscure liver enlargements and jaundices which every now and then, in this country at any rate, are presented to the practitioner; and although I never met with an analogous case, yet I can recall to memory a few instances during the past three years, of Chinamen especially, many of whom are settled in this city, who have applied to me in the medical out-patient department of this hospital for the treatment of obscure, hard, massive enlargements of the liver, with or without jaundice, and in whom I am now naturally inclined to suppose that a similar cause for the disease might have existed.

The Chinese as well as the Burmese are well known to be "filthy feeders," delighting in putrid messes of half-raw fish, \&c.; they are bound by no caste prejudices (as the natives of India are) to abstain from any kind of "flesh, fish, or fowl"; they partake, moreover, of all kinds of "vegetable food." The sources from whence the larvæ of such parasites may be derived are therefore not far to be ever, to this question, my attention has been directed to a paper by Professor Leidy, of America, * who reports that he had received from Dr. J. G. Kerr, of Canton, China, a worm which " was vomited hy a Chinese boy, aged fifteen, and brought to him" (Dr. Kerr) "an hour and a half after its expulsion, when it was still alive. It had the appearance of a leech, and was red in colour, about an inch and a half long, and three-quarters of an inch where widest. Dr. Kerr also stated that a girl of four years, of English parents, living in Canton, passed from the bowels at one time nine of these worms. With these exceptions Dr. Kerr had not met with anvone who had ever seen or heard of anything of the kind." Prof. Leidy is of opinion that this parasite is a true liver-fluke. He says: "The worm exhibits some differences from $D$. hepaticum as usually described, but perhaps not sufficiently to characterise it as a distinct species." The specimen had been preserved in strong alcohol, which had doubtless contracted and reduced it in size, "but it is yet larger than the size assigned to $D$. hepaticum. It is perfectly smooth throughout, and exhibits no trace of roughness to the integument. It is ovatelanceolate in form, and gradually widens from the anterior to the posterior rounded extremity. The ventral acetahulum is twice the size of the mouth, and is situated about its own diameter behind it. The genital organ with the exserted spiral penis is placed just in advance of the ventral acetabulum. The measurements of the worm in its present condition are as follows:-Length, 17 lines; width at the posterior third, 7 lines; thickness near centre, 1 line; diameter of mouth, $\frac{2}{5}$ line ; diameter of acetabulum, $\frac{4}{5}$ line."

With respect to the identification of the distoma found by me, I have carefully and diligently searched such works as are here accessible (works of reference being very few and with difficulty attainable in this conntry), especially the classical helmintholographs of Dr. Cobbold, $\dagger$ of Van Beneden, ${ }^{+}$and of Leuckart, $\S$ but have been unable to find the description of any distoma which possesses the anatomical peculiarities that distinguish the one now under consideration. That it is not the ordinary D. hepaticum there can hardly be any doubt. It is more closely allied to the D. lanceolatum of Mehlis; but, apart from certain differences in size and general conformation, there are very important differences in the position and construction of the male and female reproductive organs between these two species. To enter into an arcount of these minutely would occupy too much space, and, moreover, does not coincide with the primary or principal object $I$ have had in view in the publication of the history of this case. I have been moved thereto more by pathological than purely anatomical considerations; nevertheless, I think I may be able to express my impressions with respect to the latter by exhibiting in a tabular form some of the more prominent differentiating peculiarities of these three distomata.| Thus:-

\begin{tabular}{|c|c|c|c|}
\hline & D. Hepaticum. & D. Lanceolatum. & New Liver-fluke. \\
\hline Length & $\frac{3}{4} "$ to $1^{\prime \prime}$. & ${ }_{3}^{11 \prime}(8.9 \mathrm{~mm})$. & $\frac{7}{10} "$. \\
\hline Breadth $\quad \ldots$ & $\frac{1}{2} "$ to $\frac{2}{3} "$ & $1 \frac{1}{2} "$. & $\begin{array}{l}10 \\
\frac{11}{7}\end{array}$ \\
\hline Oral sucker $\quad \ldots \quad \ldots$ & Smaller than ventral. & About same size. & Larger than ventral. \\
\hline Integument $\quad \ldots \quad \ldots$ & $\begin{array}{l}\text { Covered by minute } \\
\text { spines. }\end{array}$ & Smooth. & Smooth. \\
\hline Intestinal canal & Branched. & $\begin{array}{l}\text { Not branched. Terminates at } \\
\text { lower fourth of body. }\end{array}$ & $\begin{array}{l}\text { Not branched. Extends through } \\
\text { the whole length of body to }\end{array}$ \\
\hline $\begin{array}{l}\text { Male reproductive } \\
\text { organs }\end{array}$ & $\begin{array}{l}\text { Form a series of } \\
\text { spread-out vermi- } \\
\text { form tubes. }\end{array}$ & $\begin{array}{l}\text { Form two distinct globular } \\
\text { testes, placed one above the } \\
\text { other in the median line } \\
\text { directly below the ventral } \\
\text { sucker. }\end{array}$ & $\begin{array}{l}\text { Form one or two globular testes, } \\
\text { occupying the lower third of } \\
\text { the body below the female re- } \\
\text { productive organs, and are } \\
\text { connected with a very remark- } \\
\text { able development (recepta- } \\
\text { culum seminis?). }\end{array}$ \\
\hline $\begin{array}{l}\text { Female reproductive } \\
\text { organs }\end{array}$ & ...... & $\begin{array}{l}\text { Occupy central and hinder parts } \\
\text { of body below the testes. }\end{array}$ & $\begin{array}{l}\text { Occupy the anterior and middle } \\
\text { third of the body above the } \\
\text { testes and seminal apparatus. }\end{array}$ \\
\hline Ovum... $\quad \ldots \quad \ldots \quad \ldots$ & $\frac{1}{18 \sigma} \times \frac{1}{27}$. & About $\frac{1}{60} " \times \frac{1}{30} "$. & $\sin ^{1} \times \frac{1}{1686}$. \\
\hline
\end{tabular}

sought. In the present instance, I regret to say, I have been unable to gain any information as to the antecedent history and habits of the deceased. The "friend" who brought him to the hospital never reappeared, and the body after death was "unclaimed." With reference, how-
* Proceedings of Acad. Nat. Sciences of Philadelphia, Part iii., p. 364. + Enlozoa and the Internal Parasites of Man. ₹ Mémoire sur les Vers Intestinaux.

Die Mensehlichen Parasiten.

il I need hardly refer to the $\mathrm{D}$. conjunctum of Cobbold. Although the anatomical "arrangement of parts" in this little fluke has a somewhat 
In conclusion, I have to acknowledge my great indebtedness to my friend Dr. T. R. Lewis, who has afforded me much kindly assistance and encouragement throughout this research, and I would add that $I$ intend to forward by the earliest opportunity to Professor Parkes, of Netley, a portion of the liver and several specimens of this distoma for the museum of the Royal Victoria Hospital.

Calcutta.

\section{POPLITEAL ANEURISM CURED BY AN EXTEMPORISED COMPRESSOR.}

\author{
BY NATHANIEL ALCOCK, \\ SURGBON, ARMY MRDICAL DEPARTMENT.
}

M. H-, aged thirty-eight years, wife of a private in the 47th Regiment, was admitted into the Female Hospital, Aldershot, on July 8th, 1875. For more than six months she had felt undefined shooting pain about the right knee, without, however, being incapacitated from her usual em. ployment. On Sunday, July 5th, she went as heretofore to the North Camp chapel, carrying in her arms a child eighteen months old; when descending the incline approaching the chapel she became suddenly conscious of a painful throbbing at the back of the knee, but remained through the service, and subsequently carried home the child. The pain continued through the evening and night of Sunday, yet she went on the following morning to wash at the washhouse; by this the pain was much increased, owing to the labour of carrying water to and fro, and at night it became so intense; as to prevent all rest. On Tuesday morning she walked in great agony to the station hospital, and, returning with no little difficulty to her hut, remained lying down in accordance with the directions of the medical officer till the afternoon of the next day, when she was removed to the Female Hospital.

When seen at 6 o'clock P.M. on Wednesday, July 8th, there was an aneurism about the size of a small hen's egg, pulsating very strongily, with a feeling of forcible dilatation at each heart-stroke, as if the sac was very thin. Having in a female hospital neither the command of relays of students as in a civil hospital, nor of orderlies as in a military one, it was impossible to organise a corps of digital compressors. Accordingly, at 7 o'clock, a Carte's tourniquet was applied to the femoral, and pressure maintained with alternately complete and partial control of the circulation for four hours, but could not be continued longer owing to the pain excited. All treatment was omitted for the night.

At 11 o'clock on the day following Carte's tourniquet was again applied, a nurse's finger being made the immediate pad, as that was best borne. A second tourniquet was secured over the vessel at Scarpa's triangle, to be tightened from time to time as a relief to the first. Pressure was thus continued as completely as the patient's restlessness would admit, but was practically only intermittent, for seven hours, when it could be no longer tolerated. No appreciable alteration had taken place in the aneurism; further compression being quite impossible, the leg was at 6.30 P.M. tightly flexed upon the thigh, and left so for the night. Flexion as complete as could be accomplished by lacing the limb up in a kind of leather stays was kept up without a moment's intermission for three days and four nights.

At 10 o'clock on the 12th of July the tumour was again examined, and seemed to have become slightly less expansive, feeling as though the wall of the sac was a little thickened; but the amount gained was so very doubtful as to render the prospect of cure by this means very hopeless. Carte's tourniquet over a finger was resumed; but in an hour and a half the patient became so unmanageable from the severity of the pain that it had to be finally dispensed with, and the limb was again flexed. The treatment of the case seemed now narrowed to two alternatives-either continued anæsthesia by chloroform for eight or ten hours to

close resemblance to that in the new distoma, yet its size (about ${ }^{\frac{1}{4}}{ }^{\prime \prime}$ ) preclndes at once its being recognised as anything more than an allied species, and it has never yet been found in man. admit a perfect trial of instrumental pressure, or operation. While endeavouring to decide upon the best course to be pursued, I remembered that Dr. Bellingham had found the weight of a conical piece of lead to be borne when no instrument would be submitted to. I accordingly got from the matron a tin funnel, inserted a cork into the narrow end, and covered this with a soft pad. The funnel was then filled with shot, and the whole enclosed in a conical calico bag to prevent the shot escaping. This was applied at 6 to 8 P.M. without causing much inconvenience. It was then removed, and the limb flexed for the night.

At 9.30 A.M. on the following morning (July 13th), the aneurism being unaltered since last examination, the shotfunnel was placed over the femoral at the fold of the groin, the exact position of the vessel being indicated by a piece of soap plaster, spread on leather, pasted over it, and additional shot was poured into the bag until the circulation was completely stopped; the limb was unbent to relieve the acute pain in the front of the knee, and by the almost incredible patience of the matron and the ward nurse the weight was held in this position for twelve hours and a half without the slightest variation. At the end of that time, to my very great astonishment, all pulsation in the tumour was at an end, and the aneurism cured.

For two days the funnel was applied for a few hours each day to secure the full contraction of the clot, and then was finally omitted. The total weight of the loaded funnel was $61 \mathrm{lb} .2 \mathrm{oz}$.

The collateral circulation was so effectually developed that the temperature of the limb was not at any time per. ceptibly lowered, nor has any inconvenience arisen from occlusion of the main artery.

The tumour is now (July $23 \mathrm{rd}$ ) reduced to the size of a small walnut, and is perfectly solid.

Aldershot.

\section{THE PHYSIQUE OF FACTORY CHILDREN.}

By CHARLES ROBERTS, F.R.C.S.,

IATR ASSISTANT-SURGRON TO THE VICTORIA HOSPITAL FOR SICK CHILDREN, HTC.

The evidence given by Dr. Ferguson, of Bolton, before the Royal Commission on the Factory Acts, has produced a deep impression on the public mind, and has been noticed and commented on by THe Lancer, The Times, and the public press generally. While ready to admit to the uttermost the ill effects on the constitution of children of the substitution of tea and coffee for milk in their diet, and of the degenerating effects of intemperance in the parents, and, worse still, intemperance and the use of tobacco in their progeny, I am disposed to think that Dr. Ferguson very much over-states his case, and for some reason, which requires explanation, his experience of the degeneracy of the factory population is not borne out by wider and equally exact and careful observation; but, on the contrary, there is evidence of the improvement of the physique of the factory children.

In the winter of 1872 and $73 \mathrm{I}$ was engaged with others in investigating this subject, for the purposes of Dr. Bridges's and Mr. T. Holmes's "Report to the Local Government Board on the Proposed Changes in Hours and Ages of Employment in Textile Factories," and I had opportunities of examining, weighing, and measuring many thousands of factory children in Bolton (Dr. Ferguson's town), Bury, Rochdale, and other manufacturing districts, and afterwards of comparing them with the children in York and the agricultural districts in the North Riding; and the following notes, taken at the time and published in the Report, will show the result of that investigation:-

The factory children are fairly well developed, and remarkably free from constitutional diseases; and, with the exception of a disposition to flat-foot and a relaxed state of the ligaments of the knee- and elbow-joints, are free from deformities.

In general conformation of body the factory children do not compare favourably with the agricultural. In the manufacturing towns the children are short of stature, have 